Digital Object Identifier (DOI): 10.38087/2595.8801.61

\title{
A RELAÇÃO DEMOCRÁTICA: PRINCÍPIO PARA PRÁTICA DA EDUCAÇÃO INCLUSIVA
}

Ilma de Lima Simões dos Santos

Márcio de Almeida Alexandre

Alunos Unilogos

\section{RESUMO}

O objetivo deste artigo é compreender a educação inclusiva e a concepção de Freire, Rancière e Jacotot na construção das práticas democráticas, que nos propõe, uma filosofia de educação capaz de nos orientar a uma crítica do princípio igualitário, tendo como objetivo compreender a construção das práticas democráticas na educação inclusiva, enquanto o pensamento de Rancière é uma concepção sobre o ato de educar, a compreensão do conceito de inteligência e para Rancière se apoia na experiência pedagógica de Joseph Jacotot. É em sua facilidade histórica e empírica que ele encontra elementos para desenvolver uma reflexão sobre a educação que ao fundamentar-se no princípio igualitário pode propor tanto uma nova pedagogia de ensino, como também uma ideia normativa renovada para a compreensão do que entender por uma educação inclusiva bem-sucedida.

Palavras-chave: Educação Inclusiva, Relação Democrática, Freire, Práticas Educativas. 


\section{1- INTRODUÇÃO}

Historicamente, o modelo de educação derivava-se de mudanças político-econômicas e socioculturais foram acompanhadas pela progressiva escolarização dos meios de educar e instruir os indivíduos, sendo tais práticas cada vez mais associadas à divisão do trabalho, à experiência da vida social, cultural e econômico das democracias liberais e a complexidade e diferenciação social e, consequentemente, à distribuição desigual dos conhecimentos públicos.

A educação e responsável pela formação e transformação do homem propiciando-lhe os meios adequados ao exercício de sua liberdade, autonomia e humanidade. O homem se humaniza pela educação, liberdade, racionalidade e moralidade e são fundamentos da filosofia de Kent (1999, p.107) ${ }^{1}$ que também se constituem em fundamentos da educação.

Brito $(2009)^{2}$ destaca padrão básico e que proporcionam raciocínio, são eles os princípios que fazem parte da vida escolar dos alunos: Soberania (Razão), Individualidade (Variedade), Governo (Liberdade), Caráter (Trabalho), Mordomia (Zelador), Semear e Colher (Obediência), União (Aliança).

Em sua proposta libertadora, Freire define pensar certo como uma das exigências para a dialogicidade, portanto, sem a desconstrução de uma cultura de opressão e, dialeticamente, a instauração de uma cultura dialógico - libertadora. Ou seja, a partir da pedagogia do oprimido, Freire concebe pensar certo como um horizonte de uma nova educação, que por sua vez, requer a formação de um novo ser humano através da luta por libertação (Freire, 1993). ${ }^{3}$

Nas condições de igualdade ou princípio político para a educação, talvez ninguém tenha sido tão objetivo e enfático quanto o pedagogo francês do século XIX Joseph Jacotot (17701840) ${ }^{4}$, criador do Ensino Universal, também chamado de Filosofia Panecástica, popularizado em nosso tempo por Jacques Rancière (2003). O Ensino Universal consiste justamente na afirmação do princípio de que todas as inteligências são iguais e na postulação da liberdade de método para ensinar e para aprender, a favor da emancipação intelectual dos estudantes.

Rancière relembra Jacotot é porque encontra em sua experiência de ensino elementos para uma crítica da concepção tradicional de educação. Tal concepção Rancière nomeia através de seu significante maior: "o mestre". A educação pela palavra do mestre se dá através da transmissão do conhecimento. Sua dinâmica é, como diria Paulo Freire, basicamente

\footnotetext{
${ }^{1}$ KANT Emmanuel - Géographie - Traduction de Michèle Cohen-Halimi, Max Marcuzzi et Valérie Seroussi - Ed. Aubier, Paris, 1999.

2 . BRITO, Hélvia Alvim F. Cristãos em tempo integral: vivendo os 7 princípios Bíblicos. 4.ed. Belo Horizonte: Copyright, 2009. 5Freire, P. (1987).

${ }^{3}$ FREIRE, P. Pedagogia do oprimido, Rio de Janeiro, edt. Paz e Terra, 1970.

${ }^{4}$ JACOTOT, Joseph. Enseignement Universel. Langue Mater-nelle. Louvain: H. De Pauw, 1823 
"monológica e aquisitiva" (FREIRE, 1970, p.33-44). A autoridade daquele que conhece é exercida supostamente de forma legítima com o intuito de fazer com que aquele que ignora saia de sua ignorância. Processo marcado, então, pela "progressão destes sujeitos: conhecimento das matérias do programa para a maioria, a capacidade de se tornar mestre, por sua vez, para os melhores" (RANCIÈRE, 2011, p.10)

O objetivo deste artigo é propor o entendimento das relações democráticas na educação inclusiva, sua igualdade na vida dentro e fora da escola, porque é através dele que se faz e se constrói. E o ser humano se torna propriamente humano na medida em que, conjuntamente com outros seres humanos, pela ação, modifica o mundo externo conforme suas necessidades, ao mesmo tempo, constrói-se a si mesmo.

A ação humana exercida, coletivamente, sobre a natureza e possibilita compreender e descobrir o seu próprio modo de agir. A ação prática sobre a realidade desperta e desenvolve o entendimento, a capacidade de compreensão e a emergência de níveis de abstração cada vez mais complexos.

O ser humano age sobre o meio ambiente, natural e social e, subsequentemente, reflete sobre a sua ação, seu modo de agir, seguir à ação instrumentalizado por um entendimento mais avançado e assim sucessivamente. Age, reflete, adquire um novo entendimento e assim com esse novo entendimento, volta à ação, ação esta que o obriga a uma nova reflexão e assim sucessivamente.

Forest e Pearpoint (1997, p.138-139) ${ }^{6}$ consideram que o ensino inclusivo consiste em um desafio no qual precisamos identificar como nós toleramos as pessoas que olham, agem ou pensam diferentemente daquelas ditas pessoas "comuns". Estes autores entendem outrossim que este processo nos incita a refletir sobre como seríamos e o que faríamos se também fossemos deficientes. Tais reflexões são positivas ajudam-nos a viver de forma mais consciente e a desenvolver ações que venham a diminuir os conflitos e as diferenças humanas próprias dos sentimentos segregativos.

Sassaki (1999) ${ }^{7}$ nos fez entender através do seu trabalho de investigação intitulado de "Inclusão: construindo uma sociedade para todos", que a inclusão é um processo de mudança que envolve transformação e rompimento de barreiras, na aceitação e no acolhimento da diversidade humana. Percebe-se que o paradigma da escola inclusiva convida o gestor a ultrapassar os muros de uma administração individual, para compartilhar com toda a

\footnotetext{
${ }^{5}$ RANCIÈRE, J. O mestre ignorante: cinco lições sobre a emancipação intelectual, Belo Horizonte, edt. Autêntica, 2011.

${ }^{6}$ FOREST, M.; PEARPOINT, J. Inclusão: um panorama maior. In: MANTOAN, M. T. E. (Org.) A integração de pessoas com deficiência: contribuições para uma reflexão sobre o tema. São Paulo: Memnon, 1997. Cap.22, p.137-141.
}

7. SASSAKI, Romeu Kasumi. Inclusão: Construindo Um a Sociedade Para Todos. 3ª edição. Rio de Janeiro: WVA, 1999. 
comunidade escolar os seus anseios e novas estratégias para garantir acesso e aprendizagem a todos.

\section{2- REFERENCIAL TEÓRICO}

Na prática pedagógica, o educador é aquele que, tendo adquirido o nível de cultura necessário para o desempenho de sua atividade, dá direção ao ensino e à aprendizagem ${ }^{8}$. Ele assume o papel de mediador entre a cultura elaborada e acumulada pela humanidade, e o educando. $\mathrm{O}$ professor fará a mediação entre o coletivo da sociedade (os resultados da cultura) e o individual do aluno. Ele exerce o papel de um dos mediadores sociais entre o universal da sociedade e o particular do educando.

\subsection{CONTRUÇÃO DE RELAÇÕES DEMOCRATICAS}

Segundo Aristóteles ${ }^{8}$ (2001, p.52) a matéria prima do educador é a esperança no ser humano. O homem está corrompido. O ser humano precisa ser restaurado. É com esta esperança na restauração humana, que os educadores devem trabalhar. Como apresentado por Aristóteles, a virtude é algo a ser trabalhado com muito esforço, sendo ela possível de ser alcançada.

Paulo Freire aporta os níveis de uma ação libertadora: o educador reflete sobre o modo como ele próprio trabalha, para a mudança ou para a reprodução do sistema. Nesse estágio, busca soluções para as crises, situações-limite e se superando quanto ao processo anterior. Só então despe as velhas respostas e aprende as novas e substitui o velho por um novo modo de agir e atuar.

Já na pedagogia de Paulo Freire ${ }^{9}$ propõe um ensino na base do diálogo, a liberdade e ao exercício de busca ao conhecimento participativo e transformador. Uma educação que esteja disposta a considerar o ser humano como sujeito de sua própria aprendizagem e não como mero objeto sem respostas e saber. Sua vivência, sua realidade e essencialmente sua forma de enxergar e ler o mundo precisam ser considerados para que esta aprendizagem se realize. Nesse sentido, Paulo Freire construiu sua crítica a respeito de uma comprovada enfermidade da qual sofre a educação em nossa sociedade. Enfermidade essa que debilita o potencial humano quando a educação deveria estimular a libertação da consciência para o desenvolvimento da potencialidade criativa e emancipação do sujeito social. Essa característica presente no modelo de educação bancária faz com que se entenda o educando como um mero depósito de conhecimentos e informações.

Freire coloca uma questão totalmente original a respeito da prática educativa; não como algo a ser "doado" por quem sabe a quem não sabe; mas, sim, como uma forma de os seres

\footnotetext{
${ }^{8}$ ARISTÓTELES. Ética a Nicômacos. Trad. Mário Gama Kury. 4. ed. Brasília: UNB, 2001, p.52, 53.

${ }^{9}$ Freire, P. (1987). Pedagogia do oprimido (17 ${ }^{\mathrm{a}}$ ed.). Rio de Janeiro: Paz e Terra.
} 
humanos se apropriarem, conscientemente, de sua realidade para, assim, terem condições de transformá-la. Concepção essa em que:

"[...] a única margem de ação que se oferece aos educandos é a de receberem os depósitos, guardá-los e arquivá-los. [...].” (FREIRE, 1981, p. 66 ). ${ }^{10}$ Isto é, o sujeito apenas recebe e arquiva passivamente aquilo que lhe é repassado.

A palavra verdadeira é direito de todos, e não privilégio de poucos. Não se dialoga sozinho, nem se faz por prescrição, na relação eu-outro, quando se rouba a palavra de outrem. $O$ diálogo requer encontro entre homens pronunciando o mundo, mediatizados por ele. $\mathrm{O}$ diálogo não pode ser simples depósito de ideias de alguns sobre outros (FREIRE, 1987).

A palavra inautêntica [...] resulta da dicotomia que se estabelece entre seus elementos constituintes. Assim é que, esgotada a palavra de sua dimensão de ação, sacrificada, autenticamente, a reflexão também, se transforma em palavraria, verbalismo, blábláblá. Por tudo isto, alienada e alienante. É uma palavra oca, da qual não se pode esperar a denúncia do mundo, pois que não há denúncia verdadeira sem compromisso de transformação, nem este sem ação. Se, pelo contrário, se enfatiza ou exclusiva a ação, com sacrifício da reflexão, a palavra se converte em ativismo. Este, que é ação pela ação, ao minimizar a reflexão, nega também a práxis verdadeira e impossibilita o diálogo (FREIRE, 1987, p. 44, grifos nossos).

A educação problematizadora - libertadora requer educadores democráticos que conduzam o desenvolvimento da capacidade crítica dos educandos, sua curiosidade e sua insubmissão. $\mathrm{O}$ exercício da rigorosidade metódica, que favorece a aproximação dos objetos cognoscíveis, envolve educadores e educandos críticos, desafiadores, comprometidos verdadeiramente com a realidade, e não intelectuais mecanicamente memorizadores. Daí a importância do papel do educador, cuja tarefa não é apenas de ensinar conteúdos, conhecimentos acumulados, mas, sobretudo, de ajudar o educando a organizar o seu pensamento reflexivamente, a pensar certo (FREIRE, 1996) ${ }^{11}$

A educação promove estratégias para a formação do cidadão e, consequentemente, a prática da cidadania e a escola como uma instituição a formar pessoas de modo a modificá-la positivamente. 
A obra o mestre ignorante, é conhecida, em que Jacques Rancière (2003) ${ }^{12}$ resgata a figura do legendário Joseph Jacotot, que no século XIX afirmou a igualdade intelectual dos seres humanos como princípio de uma educação emancipadora, do povo. Em entrevista publicada um ano após o lançamento da referida obra no Brasil, Rancière observa algumas diferenças entre Joseph Jacotot e Paulo Freire, dois defensores da emancipação: o primeiro afirma uma emancipação intelectual e individual, baseada justamente no princípio da igualdade das inteligências; já Paulo Freire pensa numa emancipação social. Contudo, sugere Rancière, essa diferença se assenta num ponto comum: "Há, pois, uma distância entre as intenções da emancipação intelectual jacotista e movimentos como o de Paulo Freire. Mas há algo em comum, no processo de emancipação intelectual, como vetor de movimentos de emancipação política que rompem com uma lógica social, uma lógica de instituição" (VERMEREN; CORNU; BENVENUTO, 2003). ${ }^{13}$

\section{2-2 COERÊNCIA NAS AFIRMAÇÃO DE IGUALDADE DE PAULO FREIRE}

Regressemos à afirmação freireana de que "Ninguém é superior a ninguém". Para isso, façamos um exercício de lógica. Há três afirmações que podem se desprender, logicamente, dela. A primeira é igualmente negativa: "Ninguém é inferior a ninguém". Superior e inferior são termos semanticamente dependentes, relativos: se não há ninguém superior a ninguém, necessariamente não há também ninguém inferior a ninguém. Se não há superiores, necessariamente não há inferiores. Isso é o que parece dizer Paulo Freire quando aponta as consequências negativas que haveria se um educador ou educadora se considerasse superior aos educandos ou educandas.

A segunda proposição que se desprende daquela é também negativa: "ninguém é desigual a ninguém", e comporta uma espécie de reunião das duas anteriores. $\mathrm{O}$ conceito desigualdade abrange os de superioridade e inferioridade, isto é, a superioridade e a inferioridade são duas formas de desigualdade. Desde essa lógica, se não há superiores e inferiores também não há, portanto, desiguais.

A terceira proposição é afirmativa. Se não há desiguais, então só pode haver iguais. Assim, a terceira proposição que se desprende daquela primeira de Paulo Freire ("Ninguém é superior a ninguém") é "Todos somos iguais". A frase expressa afirmativamente a igualdade, justamente o que as outras três resguardam negando ora a superioridade, ora a inferioridade, ora a reunião de ambas, bem como a desigualdade.

\footnotetext{
${ }^{12}$ RANCIÈRE, Jacques. O mestre ignorante. Belo Horizonte: Autêntica, 2003

${ }^{13}$ VERMEREN, Patrice; CORNU, Laurence; BENVENUTO, Andrea. Atualidade de O mestre ignorante. Educação \& Sociedade, Campinas, v. 24, n. 82, p. 185-202, abr. 2003. Dossiê: Igualdade e liberdade em educação. A propósito de O mestre ignorante. Organizadores: Jorge Larrosa e Walter Kohan.
} 
O que podemos perceber claramente das indagações a sugestão que Paulo Freire faz, que temos incorporado é que não há educação libertadora, politicamente correta e justa, isto é, não se abre uma política interessante para a educação enquanto educadores, educadoras e educandos se colocarem acima - ou abaixo - uns dos outros.

\subsection{JACOTOT E A IGUALDADE AO LONGO DO TEMPO}

O Ensino Universal consiste justamente na afirmação do princípio de que todas as inteligências são iguais e na ajuda da liberdade de método para ensinar e para aprender, a favor da emancipação intelectual dos estudantes. Dentre os que tratam a igualdade como condição ou princípio político para a educação, talvez ninguém tenha sido tão claro e enfático quanto o pedagogo francês do século XIX Joseph Jacotot (1770-1840), criador do Ensino Universal, também chamado de Filosofia Panecástica, popularizado em nosso tempo por Jacques Rancière (2003). Assim, para Jacotot, só é possível uma educação emancipadora a partir do princípio da igualdade das inteligências: só há emancipação quando todos os seres humanos são intelectualmente iguais, e isso porque, na verdade, só havia uma coisa a ser ensinada: a crença na igualdade das inteligências. Contudo, as experiências de Jacotot, haviam comprovado que o método não resistia à sua captação institucional. Ele não se destinava a educar as massas, mas a revelar a cada um a sua natureza de sujeito intelectual.

Há dois níveis de ignorância afirmados por quem ensina, segundo o ensino universal: ele(a) ignora o que seu aluno(a) aprende, mas, sobretudo, ignora a desigualdade das inteligências que toda instituição escolar pressupõe, sobre a qual ela se funda. Eis o sentido mais profundo de sua ignorância: uma recusa, não aceitação.

No ensino universal, não há método para ensinar, nem para aprender. O método é o de quem aprende. A liberdade do professor para ensinar faz a liberdade do aluno para aprender. E quem aprende livremente pensa e vive livremente.

Jacotot, por sua vez, afirmava que não existem asnos ou bois entre os homens, que todo homem, pelo fato mesmo de ser humano, é intelectualmente capaz. Apenas é preciso que se reconheça que em cada manifestação intelectual pode-se encontrar o todo da inteligência humana. Pois uma vez que se foi capaz de aprender alguma coisa, se é sempre capaz de aprender qualquer outra, bastando que se queira, que se encontre uma razão para tanto. Por isso, vontade e razão podem ser consideradas sinônimos, são dois nomes para aquilo que faz um sujeito agir, buscar, aprender por si próprio.

Assim, o Ensino Universal se destina, sobretudo, àqueles não se conhecem a si mesmos como seres de vontade, capazes não só de desejar, mas de conduzir o próprio desejo.

O que Jacotot propunha era acolher seus pensamentos no que se entendia por vontade, mas talvez mostrasse onde encontrar as respostas para esse método de igualdade ou método de vontade, de qualquer forma Jacotot não impunha realmente como explicar à vontade. 


\subsection{A DICOTOMIA DE JACOTOT E FREIRE}

Embora as evidentes diferenças próprias entre alguém que viveu na França pós-revolução no século XIX e quem viveu no Brasil da Guerra Fria no século XX, há semelhanças significativas entre a maneira como Jacotot e Freire pensaram e viveram a educação. Segundo destacamos em outro texto (KOHAN, 2018), Paulo Freire se inscreve na tradição dos que vivem uma vida filosófica e pedagógica. Joseph Jacotot também. Para ambos, o exílio, mais ou menos forçado, é um ato político que contribui decisivamente para suas descobertas e práticas educacionais, suas apostas filosóficas e também para os efeitos políticos dessas descobertas entre as camadas mais populares. Apesar do exílio, Paulo Freire vive a dificuldade e dureza como uma experiência finalmente positiva na sua trajetória.

Uma outra analogia importante é que ambos são usualmente associados a métodos: Jacotot ao método universal, Freire a um método para a alfabetização de jovens e adultos. Contudo, para nenhum deles existe, de fato, algo assim como um método, ou, para dizê-lo, mais radicalmente, o método não é uma das questões educacionais mais relevantes, mas, sim, o sentido político de se trabalhar com este ou aquele método. Embora ambos sejam conhecidos em função de seus métodos, para nenhum deles os métodos são decisivos. Para Jacotot, o método é o do aluno (RANCIËRE, 2003, p. 26). Para Freire, a transformação propiciada por uma educação libertadora não é uma questão de método mas "de estabelecer uma relação diferente com o conhecimento e com a sociedade" (FREIRE; SHOR, 1986, p. 28 [1987, p. $35])$.

Segundo Rancière, não há nada mais afastado de Jacotot do que um método para a "conscientização" social (VERMEREN; CORNU; BENVENUTO, 2003). Diferentemente de Paulo Freire, Jacotot afirma que a igualdade só pode se dar de indivíduo a indivíduo, mas que é impossível de ser institucionalizada ou propagada como forma de emancipação social. Contudo, como vimos, ainda que a emancipação intelectual só seja possível de forma individual, não há emancipação social que não pressuponha uma emancipação individual. Nesse sentido, poder-se-ia aproximar o anarquismo pessimista de Jacotot ao progressismo otimista de Paulo Freire, conforme Rancière sugere: "no processo de emancipação intelectual como vetor de movimentos de emancipação política que rompem com uma lógica social, uma lógica de instituição" (VERMEREN; CORNU; BENVENUTO, 2003, p. 199).

Paulo Freire chama essa posição de radical democrática, porque aposta ao mesmo tempo na liberdade, não renuncia assumir a preceitos docente, sem por isso negar a liberdade dos alunos, na medida em que confia na sua capacidade de reflexão. O trabalho conscientizador do educador não diz respeito à transmissão de um saber libertador, mas ao estímulo à reflexividade do aluno para que possa "desvendar a manipulação real e os mitos da sociedade" (FREIRE; SHOR, 1986, p. 104 [1987, p. 172]). 


\subsection{PRINCÍPIO DE IGUALDADE PARA A EDUCAÇÃO}

O princípio da igualdade significa, por um lado, que dentro da relação pedagógica as desigualdades que operam fora dela estão suspensas ou interrompidas (MASSCHELEIN, SIMONS, 2013). A relação pedagógica pode se dar num marco institucional ou fora dele, num plano informal, mas a suspensão das desigualdades é uma exigência de uma política interessante para a educação, seja qual for o marco em que ela acontece. Isso significa que, se quem ensina e quem aprende não se posicionam como iguais enquanto participantes dessa relação de ensino e aprendizagem, a força política da sua prática educacional vê-se afetada significativamente.

As liberdades básicas, como demonstra o próprio Rawls (2003, p. 145), compreendem: a liberdade de pensamento, a liberdade de consciência, a liberdade de associação, as liberdades políticas, as liberdades incluídas na noção de liberdade e de integridade da pessoa, os direitos e liberdades protegidos pelo Estado de Direito

As concepções inspiradas em Joseph Jacotot e Paulo Freire, que a igualdade é um princípio importante e transversal para uma política interessante na relação pedagógica. Essa igualdade é afirmada como princípio ou início - não como meta ou objetivo -, e atravessa diversos campos: a vida e a capacidade intelectual, mas também os saberes, o pensamento, os afetos, os não saberes.

Ao combinar os dois princípios, Rawls $(2002)^{14}$ reconhece que as desigualdades naturais e sociais são imerecidas e precisam ser reparadas e compensadas, e o princípio da diferença é o que garante essa reparação, visando à igualdade.

Ainda dentro da estrutura básica, mais especificamente no segundo princípio de justiça, o da igualdade equitativa de oportunidades, Rawls demonstra a preocupação com a excessiva dominação econômica que possa levar à dominação política, em detrimento das condições sociais, econômicas e culturais, como as oportunidades de educação, propriedade e de treinamento profissional para as pessoas, independentemente da sua classe social.

"A lgualdade equitativa de oportunidades significa aqui igualdade liberal. Para alcançar seus objetivos, é preciso impor certas exigências à estrutura básica além daquelas do sistema de liberdade natural. É preciso estabelecer um sistema de mercado livre no contexto de instituições políticas e legais que ajuste as tendências de longo prazo das forças econômicas a fim de impedir a concentração excessiva da propriedade e da riqueza, sobretudo aquela que leva à dominação política. A sociedade também tem de estabelecer, entre outras coisas, oportunidades iguais de educação para todos independentemente da renda familiar (§ 15)" (Rawls, 2002a, p. 62, grifo nosso).

\footnotetext{
${ }^{14}$ RAWLS, John. Justiça como equidade: uma reformulação. Tradução de Claudia Berliner. São Paulo: Martins Fontes, 2003
} 
A exclusão e a discriminação, constituem o caminho para a segregação na vida e marcam, de forma profunda, o desenvolvimento de crianças e adolescentes considerados fora do padrão, os diferentes. Mantoan (2000) ${ }^{15}$ afirma que "a segregação, as práticas de identificação e de rotulação são consideradas discriminatórias, desrespeitando os direitos de participação de todos na vida comunitária" (p. 31).

O respeito a autonomia e a dignidade de cada um é um imperativo ético e não um favor que podemos ou não um favor que podemos conceder uns aos outros. A partir dos atendimentos realizados com os estudantes observamos avanços significativos em atividades que antes eram realizadas com auxílio e que a partir das intervenções o estudante realiza de forma espontânea (Freire, 1996, p.58). ${ }^{16}$

\section{3- CONSIDERAÇÕES FINAIS}

O risco é tematizado em várias obras de Paulo Freire. Na obra Pedagogia da Indignação, Freire reitera sua compreensão de que "não haveria cultura nem história sem risco, assumido ou não; quer dizer, risco de que o sujeito que o corre se acha mais ou menos consciente" (FREIRE, 2000, p. 30). Assim, o autor nos desafia à tomada de consciência da educação como risco. Na Pedagogia da Autonomia, ao apresentar o tema Ensinar exige risco, aceitação do novo e rejeição a qualquer forma de discriminação (FREIRE, 1996, p. 39), o autor argumenta que a disponibilidade ao risco e a aceitação do novo são condições para um dos saberes necessários à prática educativa, o pensar certo.

Paulo Freire representa um marco na história da educação brasileira e de outros países. Ao criar comparações implicadas da educação, bancária para nomear as práticas educativas que reduzem os educandos a meros depositários de informação, tornou-se referência por sua proposição acerca de uma educação problematizadora e libertadora, cuja teorização veio a constituir-se como uma das tendências pedagógicas no campo da pedagogia progressista (FREITAS, 2014).

Percebe-se a grande contribuição de Paulo Freire na temática de inclusão escolar, pois aborda o ensinar de modo dialógico, transformador e crítico, mesmo que em suas teorias não ter abordado tema, auxiliando no desenvolvimento de métodos de educação para todos e ainda depreender (e exercer) a educação como risco é importante para recuperar os sentidos e as finalidades da educação, para além de promover a aprendizagem.

A correlação dos elementos sociais, assim como os filosóficos, aliados ao aparato do processo educacional (pedagógico) é o que possibilita a valorização do indivíduo. Esta educação, acima de tudo assume a postura de estar aberta a possibilidades para a construção da identidade do indivíduo, numa teia de relações que o leva a (trans) formação e a condição de liberdade.

\footnotetext{
${ }^{15}$ MANTOAN, Maria Teresa Egléret aí. A integração de pessoas com deficiência: contribuições: uma reflexão sobre o tema. São Paulo: 2000.

${ }^{16}$ FREIRE, P. Pedagogia da autonomia: saberes necessários à prática educativa. 25.ed. São Paulo: Paz e Terra, 1996.
} 


\section{BIBLIOGRAFIA}

1. KANT Emmanuel - Géographie - Traduction de Michèle Cohen-Halimi, Max Marcuzzi et Valérie Seroussi - Ed. Aubier, Paris, 1999.

2. BRITO, Hélvia Alvim F. Cristãos em tempo integral: vivendo os 7 princípios Bíblicos. 4.ed. Belo Horizonte: Copyright, 2009. 5Freire, P. (1987).

4. FREIRE, P. Pedagogia do Oprimido, Rio de Janeiro, edt. Paz e Terra, 1970.

5. RANCIÈRE, J. O mestre Ignorante: Cinco Lições sobre a Emancipação Intelectual, Belo Horizonte, ed. Autêntica, 2011.

6. JACOTOT, Joseph. Enseignement Universel. Langue Mater-nelle. Louvain: H. De Pauw, 1823

SecondeÉdition. Louvain: De l'Imprimerie de H. de Pauw, 1824

Enseignement universel. Langue Étrangère. l'Imprimerie de H. de Pauw, 1824.Enseñanza universal. Lengua Materna . Buenos Aires:Cactus, 2008.

7. FOREST, M.; PEARPOINT, J. Inclusão: um Panorama Maior. In: MANTOAN, M. T. E. (Org.) A integração de pessoas com deficiência: contribuições para uma reflexão sobre o tema. São Paulo: Memnon, 1997. Cap.22, p.137-141.

9. SASSAKI, Romeu Kasumi. Inclusão: Construindo Uma Sociedade Para Todos. $3^{\text {a }}$ edição. Rio de Janeiro: WVA, 1999.

10. ARISTÓTELES. Ética a Nicômacos. Trad. Mário Gama Kury. 4. ed. Brasília: UNB, 2001, p.52, 53.

11. Freire, P. (1987). Pedagogia do oprimido (17 ${ }^{\mathrm{a}}$ ed.). Rio de Janeiro: Paz e Terra.

12. Ação Cultural para a Liberdade. 5. ed. Rio de Janeiro:

Paz e Terra, 1981.

13. FREIRE, Paulo. Letters to Cristina: Reflections on my life and work. Translated by Donaldo Macedo. New York: Routledge, 1996.

14. RANCIÈRE, Jacques. O Mestre Ignorante. Belo Horizonte: Autêntica, 2003.

15. VERMEREN, Patrice; CORNU, Laurence; BENVENUTO, Andrea. Atualidade de O mestre Ignorante. Educação \& Sociedade, Campinas, v. 24, n. 82, p. 185-202, abr. 2003. Dossiê: Igualdade e liberdade em educação. A propósito de $\mathrm{O}$ mestre ignorante. Organizadores: Jorge Larrosa e Walter Kohan. 
16. FREIRE, Paulo; SHOR, Ira. Medo e Ousadia: O Cotidiano do Professor. São Paulo: Paz e Terra, 1986.

17. VERMEREN, Patrice. Nada está en nada. O todo el mundo sabe la lógica: el método de enseñanza universal de Joseph Jacotot y la emancipación intelectual en las clases pobres. Hermenéutica Intercultural, Santiago, Chile, n. 28, p. 211-227, 2017.

18. GADOTTI, Moacir; CARNOY, Martin (Org.). Reinventando Paulo Freire: a práxis do Instituto Paulo Freire. São Paulo: Instituto Paulo Freire; Lamann Center; Stanford Graduate School of Education, 2018.

19. VERMEREN, Patrice. Nada está en nada. O todo el mundo sabe la lógica: el método de enseñanza universal de Joseph Jacotot y la emancipación intelectual en las clases pobres. Hermenéutica Intercultural, Santiago, Chile, n. 28, p. 211-227, 2017.

18. FREIRE, Paulo. Pedagogia do Oprimido. Rio de Janeiro: Paz e Terra, 1987.

19. FREIRE, Paulo; SHOR, Ira. A pedagogy for liberation: dialogues on transforming education. Granby: Bergin \& Garvey, 1987.

20. FREIRE, Paulo. Pedagogia da Esperança: um reencontro com a Pedagogia do oprimido. 21. ed. São Paulo: Paz e Terra, 2014.

21. GADOTTI, Moacir. Paulo Freire: Uma Biobibliografia. São Paulo: Cortez, 2001.

22. RAWLS, John. Justiça como Equidade: uma reformulação. Tradução de Claudia Berliner. São Paulo: Martins Fontes, 2003.

23. . Uma Teoria da Justiça. Tradução de Almiro Pisetta, Lenita Maria Rimoli Esteves. São Paulo: Martins Fontes, 2002a.

24. MASSCHELEIN, Jan; SIMONS, Maarten. Em Defesa da Escola. Belo Horizonte: Autêntica, 2013.

25. FREIRE, P. Pedagogia da Autonomia: saberes necessários à prática educativa. 25.ed. São Paulo: Paz e Terra, 1996.

26. MANTOAN, Maria Teresa Egléret aí. A Integração de Pessoas com Deficiência: contribuições: uma reflexão sobre o tema. São Paulo: 2000.

27. FREITAS, A. L. S. de. Pedagogia da Conscientização - Um legado de Paulo Freire à formação de professores. Porto Alegre: EDIPUCRS, 2001.

28. Leituras de Paulo Freire: Uma Trilogia de Referência. Passo Fundo, RS: Méritos, 2014. v.1. 